\title{
EFECTO DE LA EDAD AL PRIMER PARTO SOBRE PARÁMETROS PRODUCTIVOS EN VACAS JERSEY DE COSTA RICA ${ }^{1}$
}

\author{
Gloriana Castillo-Badilla², Mauren Salazar-Carranza², Jaime Murillo-Herrera ${ }^{3}$, Juan José Romero-Zúñiga
}

\section{RESUMEN}

Efecto de la edad al primer parto sobre parámetros productivos en vacas Jersey de Costa Rica. El objetivo del presente trabajo fue determinar el efecto de la edad al primer parto (EPP) sobre la producción láctea en vacas Jersey. Se analizaron los registros de 28367 vacas pertenecientes a 545 hatos, registrados en el programa VAMPP Bovino 3.0 entre enero del año 2000 a diciembre del 2010. Se empleó estadística descriptiva y modelos lineales mixtos. La EPP promedio fue 29,35 meses (DE: 6,77), con una tendencia al incremento durante el periodo estudio. Se observó un efecto significativo de la EPP sobre la producción ( $\mathrm{kg} / 305$ d) en las dos primeras lactancias $(\mathrm{P}<0,0001)$. En la primera lactancia, las vacas con EPP $<25,8$ meses, con EPP entre 25,8 y 41,0 meses, produjeron $275,81 \mathrm{~kg}$ y $167,70 \mathrm{~kg}$ menos $(\mathrm{P}<0,0001)$ que aquellas con EPP >41 meses. Las vacas sin retención de placenta $(\mathrm{RMF})$ produjeron $+450 \mathrm{~kg} / 305$ días $(\mathrm{P}=0,0022)$ que con RMF; mientras, el índice de endogamia y el tipo de parto no tuvieron efecto sobre la producción. En la segunda lactancia, las variables de estudio afectaron la producción de forma similar a la primera; sin embargo, la edad al segundo parto no afectó la producción subsecuente. Hubo un efecto lineal de la EPP sobre la producción de leche de la primera y la segunda lactancia; así, la EPP, parece tener un efecto no solo sobre la primera lactancia sino, también, en el rendimiento productivo posterior.

Palabras clave: producción lechera, primera lactancia, edad al primer parto, Jersey.

\begin{abstract}
Effect of age at first calving on productive parameters in Costa Rican Jersey cows. The objective of this work was to quantify the effect of age at first calving (AFC) on milk production in the first and second lactation of specialized diary Jersey cows. Records of 28367 cows belonging to 545 specialized dairy herds, registered in the software VAMPP Bovino 3.0 between January 2000 and December 2010, were used. Descriptive statistics and linear mixed models were performed. The AFC average was 29.35 months (SD: 6.77), with a trend to increase during the study period. A significant effect of the AFC was observed on milk production $(\mathrm{kg} / 305 \mathrm{~d})$ in the first two lactations $(\mathrm{P}<0.0001)$; in the first lactation, cows with AFC $<25.8$ months or between 25.8 and 41.0 months produced -275.81 and -167.70 $\mathrm{kg} / 305 \mathrm{~d}(\mathrm{P}<0.0001)$ than those with AFC $>41$ months. Cows without retained placenta $(\mathrm{RMF})$ produced $+450 \mathrm{~kg} / 305 \mathrm{~d}$ $(\mathrm{P}=0.0022)$ than those with RMF. On the other hand, the inbreeding coefficient and type of birth had no effect on milk production. In the second lactation, the independent variables affected the milk production similarly to first lactation; however, the age at second calving did not affect the subsequent production. This study demonstrates the linear effect of AFC on first and second lactation milk production; thus, AFC seems to have an effect not only on first lactation, but also in the productive performance of second lactation.
\end{abstract}

Key words: milk production, first lactation, age at first calving, Jersey.

\footnotetext{
1 Recibido: 20 de noviembre, 2012. Aceptado: 1 de abril, 2013. Este trabajo es parte de la tesis de licenciatura de Medicina Veterinaria de la primer autora. Escuela de Medicina Veterinaria de la Universidad Nacional, Heredia, Costa Rica.

2 Apdo. postal 304-3000 Heredia.gcastiba@gmail.com, mausalazarcarranza@gmail.com

3 Escuela de Medicina Veterinaria. Universidad Nacional. Costa Rica. Apdo. postal 304-3000 Heredia, Costa Rica. Teléfono: (506) 25624566. jaime.murillo@una.cr, juan.romero.zuniga@una.cr (Autor para correspondencia).
} 


\section{INTRODUCCIÓN}

La eficiencia reproductiva determina, en gran medida, las ganancias de una empresa ganadera. En explotaciones lecheras, estas dependen de la magnitud del período de reproducción de las hembras, pues la productividad está en función de la frecuencia de parición a lo largo de la vida del animal (Casas y Tewolde 2001).

La decisión de comenzar la vida productiva de un animal se basa principalmente en el peso, el tamaño corporal y la edad. Los programas de hembras de reemplazo tienen como meta que la edad promedio al primer parto (EPP) sea de 24 meses, ya que esto implica una disminución en los costos de producción (Pirlo et al. 2000, Radostits 2001). Idealmente, bajo condiciones de pastoreo, los animales en el trópico deberían alcanzar su madurez reproductiva a los 15 meses de edad, tiempo en el cual deberían poseer el $60 \%$ del peso corporal (Radostits 2001).

Por otra parte, la producción láctea se ve afectada por los factores ambientales, la disponibilidad de alimento, el manejo y los trastornos fisiológicos y patológicos que se presenten durante lactancia, el periodo seco (González y Boschini 1996). Además, las explotaciones pecuarias en el trópico enfrentan, además, una gran variedad de microclimas que influyen en el rendimiento productivo de los animales (WingChingJones et al. 2008).

La edad adecuada de un animal a la hora del primer parto, tiene un efecto significativo en el rendimiento productivo de un animal durante su vida, así como también puede disminuir la vida productiva del bovino dentro del hato lechero (Marini et al. 2007, Haworth et al. 2008). Algunos estudios comprueban que vacas que paren a una corta edad tienen una menor producción de leche durante su primera lactancia; sin embargo, su producción total por día y su rendimiento durante su vida son significativamente mayores que aquellos animales que tuvieron su primer parto a una edad más avanzada (Radostits 2001, Bormann et al. 2002, Marini et al. 2007). Aunado a esto, se ha indicado que la reducción de la EPP puede incrementar la rentabilidad de la empresa por medio del aumento del desempeño productivo del animal durante su vida (Meyer et al. 2004). Por esa razón, las terneras deben mantenerse con un régimen nutricional adecuado para obtener una disminución en la edad de inicio de la vida reproductiva; esto sin afectar el desarrollo mamario ni comprometer el posterior desempeño productivo del animal, ya que un mal manejo de la dieta durante el periodo prepuberal puede llegar a provocar un mal desarrollo mamario y su futuro rendimiento productivo se afecta negativamente (Sejrsen y Purup 1997). Esta disminución está relacionada con el crecimiento acelerado durante el periodo prepuberal, que reduce la funcionalidad del tejido mamario y, por lo tanto, su posterior producción de leche (Ettema y Santos 2004).

Con base en estudios realizados en el periodo comprendido entre 1960 y 1982, la edad promedio al primer parto en un animal de raza Jersey fue cercana a los 25 meses, siendo este el valor más bajo en comparación con otras razas (Powell 1985). Esto sucede porque estas alcanzan su peso ideal para la inseminación de manera más precoz, debido a que se ven menos afectadas por factores ambientales, tales como temperatura y humedad (West et al. 2003, García et al. 2005). Igualmente, se caracterizan por tener grandes ventajas, respecto a las Holstein puras y los cruces Holstein x Jersey, como son su superioridad en fertilidad, excelente facilidad de parto y mayor longevidad, además de tener como ventaja la calidad de la leche, que es de gran importancia para la industria lechera (Bolívar et al. 2009).

El objetivo principal de las explotaciones lecheras es producir a un menor costo, obteniendo buenos rendimientos productivos y buena calidad de leche. Para cumplir con esta meta, la reproducción es un factor vital para lograr una producción animal eficiente (Ball y Peters 2004). El efecto de la velocidad de crecimiento, edad y peso al primer parto sobre la subsecuente producción de leche, ha sido ampliamente estudiado a través del tiempo (Solano y Vargas 1997, Andrews 2000, Ettema y Santos 2004), ya que el animal, muchas veces, no llega a la lactación con un peso corporal adecuado para soportar las exigencias que conlleva la producción de leche (Pirlo et al. 2000). Es por eso que existe un efecto significativo, y linealmente positivo, entre la EPP y la producción de leche en la primera lactancia (Solano y Vargas 1997).

Según estudios, tanto en los Estados Unidos como en el mundo, se ha observado una leve disminución de la EPP con el paso de los años siendo 25,9 meses en 1991, y de 25,4 meses para el año 2002 (USDA 2002, Hare et al. 2006). Esto puede relacionarse con el aumento en la tasa de rotación dentro del hato lechero, una mejor selección genética, o a una mejoría en la crianza de terneras que conllevan a una madurez reproductiva 
precoz. Por otro lado, autores como Casas y Tewolde (2001), afirman que la producción de leche se ve incrementada con cada día que aumenta la EPP porque el animal se presenta en mejores condiciones al parto, lo que influye positivamente sobre la producción de leche en la lactancia inmediata (Casas y Tewolde 2001).

En Costa Rica, un estudio determinó una EPP promedio de 38,8 $\mathrm{m}$ en animales Jersey (WingChing-Jones et al. 2008). Los autores atribuyeron esta alta EPP a las condiciones de pastoreo sin suplementación nutricional adecuada, que provoca limitaciones en la tasa de crecimiento y, por lo tanto, un incremento en la EPP.

Existen factores que producen variaciones en la $\mathrm{EPP}$, entre los que se incluyen las características genéticas del grupo racial, el índice de endogamia, la locación donde se encuentra el animal, así como condiciones de manejo tales como tamaño del hato y condiciones de crianza, asimismo, influyen el año y la época de nacimiento (Casas y Tewolde 2001, Ben Gara et al. 2009).

En el trópico, los sistemas de producción de leche están limitados en su nivel de producción por factores tanto genéticos como ambientales. Las condiciones del medio tropical afectan de manera considerable el comportamiento productivo de las vacas lecheras, disminuyendo su producción y condicionando el manejo de los animales, lo que limita la expresión del potencial genético. La producción de leche por vaca por año en el trópico, es aproximadamente una cuarta parte de la lograda en zonas templadas (Carvajal et al. 2002).

Entre las variables ambientales estacionales que repercuten sobre la EPP y la subsecuente producción de leche, con especial importancia en climas tropicales, están la precipitación pluvial y la humedad relativa (WingChing-Jones et al. 2008). Además, se ha determinado que en condiciones de pastoreo, la ingesta de forrajes nutricionalmente pobres pueden aumentar la EPP (Heinrichs et al. 2005).

El objetivo de este estudio fue determinar el efecto de la edad a primer parto sobre la producción láctea en vacas Jersey.

\section{MATERIAL Y MÉTODOS}

\section{Fuente de los datos}

Se trabajó con información de la base nacional de datos del Centro Regional de Informática para Producción Animal Sostenible, del Programa de
Investigación en Medicina Poblacional de la Escuela de Medicina Veterinaria de la Universidad Nacional, que utiliza el paquete informático VAMPP Bovino 3.0 (Noordhuizen y Buurman 1984) para la captura y administración de la base de datos en cada finca.

Se utilizaron los registros de 28367 vacas Jersey puras, de 544 hatos lecheros especializados de Costa Rica, durante el período 2000-2010, que presentaron las condiciones adecuadas para su procesamiento estadístico, es decir, que contaban con registros completos para todas las variables del estudio con datos plausibles (dentro de rangos biológicos probables). Estas fincas se distribuyen en las principales zonas lecheras de Alajuela, Heredia, Cartago y San José.

\section{Variables}

La variable independiente principal fue la edad al primer parto de cada vaca, siendo la producción de leche de la primera y la segunda lactancia, las variables dependientes. Las demás variables independientes para determinar el efecto sobre la producción láctea de cada lactancia se describen en los Cuadros 1 y 2 . Las variables del Cuadro 1 también fueron tomadas en cuenta al estimar los efectos sobre la producción en la segunda lactancia.

\section{Análisis estadístico}

El análisis de datos se llevó a cabo en varias fases: a) Estadística descriptiva: se realizó el cálculo de medidas de tendencia central (media y mediana) y medidas de dispersión (desviación estándar), ambas para las variables en forma continua. Se calcularon porcentajes para las variables discretas. Para ambos tipos de medidas se determinó el intervalo de confianza (IC) al 95\%. b) Estimación del efecto de la EPP sobre los parámetros productivos de la primera y segunda lactancia: se realizó mediante un modelo múltiple lineal mixto, en el cual se creó un modelo para la evaluación de cada variable dependiente (producción a 305 días de la primera lactancia y producción a 305 días de la segunda). Se asumió un manejo homogéneo a los animales del hato dentro de su categoría; y que todos estuvieron expuestos a los mismos factores medioambientales. De ese modo, el modelo de regresión lineal mixto incluyó las variables hato/año/época de parto como la variable de efecto aleatorio para controlar el posible efecto de las 
Cuadro 1. Variables utilizadas en el análisis de los efectos de la edad al primer parto sobre la producción de la primera lactancia en vacas Jersey puras de hatos lecheros especializados de Costa Rica. Enero de 2000 a diciembre de 2010.

\begin{tabular}{|c|c|c|c|c|}
\hline Variable & Condición & Tipo de variable & Nivel de variable & Descripción \\
\hline Producción de leche $1^{\circ}$ lactancia & Dependiente & $\begin{array}{l}\text { Continua } \\
\text { Discreta }\end{array}$ & $\begin{array}{l}\text { Continuo } \\
\text { Bajo } \\
\text { Medio } \\
\text { Alto }\end{array}$ & $\begin{array}{l}\text { Corregida en kg } 305 \mathrm{~d} \\
<2400 \\
2400-4302 \\
>4302\end{array}$ \\
\hline Edad al primer parto (meses) & Independiente & Politómica & $\begin{array}{c}\text { Bajo } \\
\text { Medio } \\
\text { Alto }\end{array}$ & $\begin{array}{l}<25,8 \\
25,8-41 \\
>41\end{array}$ \\
\hline Año de nacimiento & Independiente & Discreta & Ordinal & \\
\hline $\begin{array}{l}\text { Época de nacimiento de la } \\
\text { hembra }\end{array}$ & Independiente & $\begin{array}{c}\text { Discreta } \\
\text { Politómica }\end{array}$ & $\begin{array}{c}\text { Seca } \\
\text { Lluviosa }\end{array}$ & $\begin{array}{l}\text { Diciembre, enero, febrero, marzo } \\
\text { y abril. } \\
\text { Mayo, junio, julio, agosto, se- } \\
\text { tiembre, octubre y noviembre. }\end{array}$ \\
\hline Tipo de parto & Independiente & $\begin{array}{c}\text { Discreta } \\
\text { Politómica }\end{array}$ & $\begin{array}{c}\text { Normal } \\
\text { Normal con RMF } \\
\text { Distócico } \\
\text { Distócico con } \\
\text { RMF } \\
\text { Cesárea }\end{array}$ & $\begin{array}{l}\text { Normal sin asistencia. } \\
\text { Normal sin asistencia con RMF. } \\
\text { Difícil con asistencia y sin ce- } \\
\text { sárea. } \\
\text { Difícil con asistencia sin cesárea } \\
\text { y con RMF. } \\
\text { Difícil con asistencia y con ce- } \\
\text { sárea. }\end{array}$ \\
\hline Tipo de parto de la madre & Independiente & $\begin{array}{c}\text { Discreta } \\
\text { Politómica }\end{array}$ & $\begin{array}{l}\text { Normal } \\
\text { Normal con RMF } \\
\text { Distócico } \\
\text { Distócico con } \\
\text { RMF } \\
\text { Cesárea }\end{array}$ & $\begin{array}{l}\text { Normal sin asistencia. } \\
\text { Normal sin asistencia con RMF. } \\
\text { Difícil con asistencia y sin ce- } \\
\text { sárea. } \\
\text { Difícil con asistencia sin cesárea } \\
\text { y con RMF. } \\
\text { Difícil con asistencia y cesárea. }\end{array}$ \\
\hline Año del $1^{\circ}$ parto & Independiente & Discreta & Ordinal & $2000-2009$ \\
\hline Época de $1^{\circ}$ parto & Independiente & Discreta & Seca & $\begin{array}{l}\text { Diciembre, enero, febrero, marzo } \\
\text { y abril. }\end{array}$ \\
\hline
\end{tabular}

Dicotómica

Lluviosa Mayo, junio, julio, agosto, setiembre, octubre y noviembre.

\begin{tabular}{llccl}
\hline Número de lactancia madre & Independiente & Discreta & & \\
& & Politómica & 1 & Primerizas \\
& & & $2-4$ & 2 a 4 \\
& & & $\geq 5$ & 5 o más \\
\hline Zona ecológica & Independiente & Discreta & 1 a 10 & Según la clasificación de zonas de \\
& & & & vida de Holdridge (1987). \\
\hline Endogamia & Independiente & Discreta & Bajo & $<6,25 \%$ \\
& & & Alto & $\leq 6,25 \%$ \\
\hline
\end{tabular}

ISSN: 1021-7444 
Cuadro 2. Variables utilizadas en el análisis de los efectos de la edad al primer parto sobre la producción de la segunda lactancia en vacas Jersey puras de hatos lecheros especializados de Costa Rica. Enero de 2000 a diciembre de 2010.

\begin{tabular}{|c|c|c|c|c|}
\hline Variable & Condición & Tipo de variable & Nivel de variable & Descripción \\
\hline $\begin{array}{l}\text { Producción de leche } 2^{\mathrm{a}} \text { lactancia } \\
(\operatorname{kg} 305 \mathrm{~d})\end{array}$ & Dependiente & $\begin{array}{l}\text { Continua } \\
\text { Discreta }\end{array}$ & $\begin{array}{l}\text { Continuo } \\
\text { Bajo } \\
\text { Medio } \\
\text { Alto } \\
\end{array}$ & $\begin{array}{c}\text { Corregida en kg } 305 \mathrm{~d} \\
<2400 \\
2400-5065 \\
>5065\end{array}$ \\
\hline Edad al $2^{\circ}$ parto (meses) & Independiente & $\begin{array}{c}\text { Discreta } \\
\text { Politómica }\end{array}$ & $\begin{array}{l}\text { Bajo } \\
\text { Medio } \\
\text { Alto }\end{array}$ & $\begin{array}{c}<38,3 \\
38,3-54,3 \\
>54,3\end{array}$ \\
\hline Año del $2^{\circ}$ parto & Independiente & Discreta & Ordinal & 2000-2009 \\
\hline Época de $2^{\circ}$ parto & Independiente & Discreta & Seca & $\begin{array}{c}\text { Diciembre, enero, febrero, } \\
\text { marzo y abril. }\end{array}$ \\
\hline & & Dicotómica & Lluviosa & $\begin{array}{c}\text { Mayo, junio, julio, agosto, } \\
\text { setiembre, octubre } \\
\text { y noviembre }\end{array}$ \\
\hline $\begin{array}{l}\text { Intervalo parto - concepción } \\
\text { (días) }\end{array}$ & Independiente & $\begin{array}{c}\text { Discreta } \\
\text { Politómica }\end{array}$ & $\begin{array}{l}\text { Continuo } \\
\text { Bajo } \\
\text { Medio } \\
\text { Alto }\end{array}$ & $\begin{array}{c}<65 \\
65-132 \\
>132\end{array}$ \\
\hline Días seca (días) & Independiente & Discreta & $\begin{array}{l}\text { Bajo } \\
\text { Medio } \\
\text { Alto }\end{array}$ & $\begin{array}{c}<52 \\
52-85 \\
>85\end{array}$ \\
\hline Longitud de la $1^{a}$ lactancia (días) & Independiente & $\begin{array}{l}\text { Continua } \\
\text { Discreto } \\
\text { Politómica }\end{array}$ & $\begin{array}{l}\text { Continuo } \\
\text { Bajo } \\
\text { Medio } \\
\text { Alto }\end{array}$ & $\begin{array}{c}<255 \\
255-343 \\
>343\end{array}$ \\
\hline Longitud de la $2^{\text {a }}$ lactancia (días) & Independiente & $\begin{array}{l}\text { Continua } \\
\text { Discreta } \\
\text { Politómica }\end{array}$ & $\begin{array}{l}\text { Continuo } \\
\text { Bajo } \\
\text { Medio } \\
\text { Alto }\end{array}$ & $\begin{array}{c}<252 \\
252-355 \\
>355\end{array}$ \\
\hline
\end{tabular}

variables comunes a todos los animales, tomando en cuenta su respuesta individual.

El modelo estadístico para la producción en la primera lactancia fue: + eijklm

Yijklm $=\mu 0+\mathrm{Epp}_{\mathrm{i}}+$ hae $_{\mathrm{j}}+\mathrm{eco}_{\mathrm{k}}+$ madre $_{1}+$ parto $_{\mathrm{m}}$
Donde:

Yijklm = Producción en la primera lactancia $\mu O=$ Media general

$E p p_{i}=$ Efecto fijo $i$-ésimo de la edad al primer parto de parto

$h a e_{j}=$ Efecto aleatorio $j$-ésimo del hato/año/época 
$e c o_{k}=$ Efecto fijo de la $k$-ésimo ecozona

madre $_{l}=$ Efecto fijo del 1-ésimo número de lactancias de la madre

parto $_{m}=$ Efecto fijo del m-ésimo tipo de parto

eijklm = Efecto aleatorio residual

El modelo estadístico para la producción en la segunda lactancia fue:

Yijklmno $=\mu 0+\mathrm{Epp}_{\mathrm{i}}+\mathrm{hae}_{\mathrm{j}}+\mathrm{lac}_{\mathrm{k}}+\mathrm{eco}_{1}+\mathrm{ipc}_{\mathrm{m}}+$ seca $_{\mathrm{n}}+$ part $_{\mathrm{o}}+$ eijklmno

Donde:

Yijklmn = Producción en la segunda lactancia

$\mu 0=$ Media general

$E p p_{i}=$ Efecto fijo $i$-ésimo de la edad al primer parto $h a e_{j}=$ Efecto aleatorio $j$-ésimo del hato/año/ época de parto

$l a c_{k}=$ Efecto fijo de la $k$-ésima producción en la primera lactancia

eco ${ }_{l}=$ Efecto fijo de la $l$-ésimo ecozona

$i p c_{m}=$ Efecto fijo del $m$-ésimo intervalo parto concepción de la primera lactancia

$\sec _{n}=$ Efecto fijo de los $n$-ésimos días secos en la primera lactancia

part $_{o}=$ Efecto fijo del $o$-ésimo tipo de parto

eijklmno $=$ Efecto aleatorio residual

Los análisis estadísticos se realizaron con el programa SAS versión 9.2 (SAS 2009).

\section{RESULTADOS Y DISCUSIÓN}

Efecto conjunto de la edad al primer parto y de las variables de tiempo, lugar $y$ animal sobre la variable producción a 305 días de la primera lactancia

Las hembras con una EPP baja y media presentaron una producción de $275,81 \mathrm{~kg}$ y $167,70 \mathrm{~kg}$ menos $(\mathrm{P}<0,0001)$ que aquellas que tuvieron una edad alta, las cuales produjeron un promedio estimado de 3929 $\mathrm{kg}$ (Cuadro 3). Este resultado concuerda con lo reportado en otros estudios que afirman la existencia de una correlación positiva entre el incremento de la producción de leche y el aumento de la EPP (Powell 1985, Pirlo et al. 2000, Ettema y Santos 2004, Haworth et al. 2008). Bailey y Currin (2009), reportan una asociación positiva entre el peso de la novilla al primer parto y la producción de leche en novillas Holstein mayores de 24 meses, de modo que el incremento en la edad producto de la búsqueda de un peso adecuado para el primer parto, conduce a una mayor producción de leche en esa primera lactancia. Otros autores mencionan que una EPP por debajo de los 23 meses comprometen el rendimiento de la producción en la primera lactancia, así también como la composición de la leche y el desempeño productivo (Haworth et al. 2008); esto debido a que la EPP está estrechamente relacionada a la tasa de crecimiento y al desarrollo estructural de la ubre para producir leche, etapas que tienen lugar en el periodo prepuberal (Sejrsen y Purup 1997, Solano y Vargas 1997, Macdonald et al. 2005, Haworth et al. 2008). Por otro lado, varios reportes indican la ausencia de relación entre la EPP y la producción de leche en la primera lactancia (Marini et al. 2001, Marini 2004).

Otros autores han observado variaciones positivas en el porcentaje de grasa en la leche, consecuente con variaciones en la EPP; según estos autores, el valor de grasa y proteína total en leche se ve incrementada en vacas con una EPP mayor ( $>25$ meses) que en aquellas que paren a una edad media (23-25 meses) o baja ( $<23$ meses) (Pirlo et al. 2000, Ettema y Santos 2004).

El efecto negativo observado sobre la producción láctea en animales con baja EPP ( $<25$ meses), se puede deber a distintos factores, tales como la ganancia de peso excesiva durante la etapa prepuberal, o la baja condición corporal del animal a la hora de empezar su primera lactancia (Pirlo et al. 2000). A estos factores, se podría sumar un manejo incorrecto de la etapa prepuberal, que conlleva a tener animales fisiológicamente no preparados para una gestación y posterior lactancia, incrementando el estrés que sufre el animal en su primer parto y afectando su desempeño productivo inmediato.

En la variable ecozona, tomando como base de comparación la zona bosque muy húmedo-Montano (bmh-M), la zona de bosque pluvial-Premontano (bp-P) es la que presenta la mayor diferencia positiva, con una producción de $1215,42 \mathrm{~kg}$ sobre la referencia $(\mathrm{P}<0,0001)$. Asimismo, las otras ecozonas presentan producciones significativamente mayores, a diferencia de la zona del bosque pluvial-Montano Bajo (bp-MB), la cual no presentó diferencia estadística respecto a la zona bmh-M (Cuadro 3).

Las zonas ecológicas con producciones de leche superiores correspondieron a bosque pluvialPremontano (bp-P), bosque muy húmedo-Premontano (bmh-P) y el bosque húmedo-Premontano (bh-P), 
Cuadro 3. Efecto de la edad al primer parto y de variables de tiempo, lugar y animal sobre la producción a 305 días de la primera lactancia, en vacas Jersey puras de hatos lecheros especializados de Costa Rica. Enero de 2000 a diciembre de 2010.

\begin{tabular}{|c|c|c|c|c|c|}
\hline Variable & Estrato & Estimado & Diferencia & E.E* & $\mathbf{P} * *$ \\
\hline Intercepto & & 3848,00 & & 203,33 & $<0,0001$ \\
\hline \multirow[t]{7}{*}{ Zona ecológica } & bh-MB & 3720,84 & 320,07 & 141,58 & 0,0238 \\
\hline & bh-P & 3925,64 & 524,86 & 143,02 & 0,0002 \\
\hline & bmh-P & 3940,27 & 539,50 & 143,74 & 0,0002 \\
\hline & bmh-T & 3614,66 & 213,89 & 137,66 & 0,0203 \\
\hline & bp-MB & 3251,10 & 149,67 & 136,78 & 0,2739 \\
\hline & bp-P & 4616,20 & 1215,42 & 149,42 & $<0,0001$ \\
\hline & bmh-M & 3400,72 & . & . & . \\
\hline \multirow[t]{2}{*}{ Tipo de parto } & Normal & 3766,06 & $-30,58$ & 61,63 & 0,6197 \\
\hline & Distócico & 3796,65 & . & . & . \\
\hline \multirow[t]{2}{*}{$\mathbf{R M F} * * *$} & Sin RMF & 4006,12 & 449,52 & 146,45 & 0,0022 \\
\hline & Con RMF & 3556,59 & . & . & . \\
\hline \multirow{3}{*}{$\begin{array}{l}\text { Edad al parto } \\
\text { (meses) }\end{array}$} & $<25,8$ & 3656,38 & $-275,81$ & 39,73 & $<0,0001$ \\
\hline & $25,8-41$ & 3761,49 & $-167,70$ & 37,18 & $<0,0001$ \\
\hline & $>41$ & 3929,16 & . & . & . \\
\hline \multirow{3}{*}{$\begin{array}{l}\text { Días de lactancia } \\
\text { (días) }\end{array}$} & $<255$ & 2965,29 & $-1350,65$ & 34,73 & $<0,0001$ \\
\hline & $255-343$ & 4062,84 & $-253,00$ & 24,94 & $<0,0001$ \\
\hline & $>343$ & 4315,84 & . & . & . \\
\hline \multirow[t]{2}{*}{ Endogamia } & $<6,25 \%$ & 3806,28 & 49,85 & 27,68 & 0,0718 \\
\hline & $>6,25 \%$ & 3756,43 & . & . & . \\
\hline
\end{tabular}

*EE $=$ Error estándar de la diferencia.

*** $\mathrm{P}=$ Valor de $\mathrm{P}$ de la diferencia.

bh- $\mathrm{MB}=$ bosque húmedo montano bajo bh- $\mathrm{P}=$ bosque húmedo premontano; bmh- $\mathrm{P}=$ bosque muy húmedo premontano; bmh- $\mathrm{T}=$ bosque muy húmedo tropical; bp-MB= bosque pluvial montano bajo; bp- $\mathrm{P}=$ bosque pluvial premontano; bmh-M= bosque muy húmedo montano. *** RMF= Retención de membranas fetales.

las cuales presentan características en común, como lo son la altitud (500-1500 $\mathrm{msnm})$ y la temperatura ambiental (promedio $18-24^{\circ} \mathrm{C}$ ), que permite el crecimiento de pastos ricos en proteína, como el Kikuyo (Pennisetum clandestinum) y Ryegrass
(Lolium sp.), con valores medios de proteína cruda de hasta $22,5 \%$ (Andrade 2006) y $25,2 \%$ (Villalobos y Sánchez 2010), respectivamente, cubriendo una alta proporción de los requerimientos necesarios para animales en producción (NRC 2001). 
Las zonas con rendimiento productivo inferior corresponden a bosque pluvial-Montano Bajo (bp-MB), bosque muy húmedo-Montano (bmh-M) y bosque muy húmedo-Tropical (bmh-T), principalmente ubicadas en el Caribe de Costa Rica y en la región adyacente a la Cordillera de Tilarán. Se observó que dichas zonas ecológicas presentan condiciones ambientales que no permiten el máximo desarrollo del potencial genético de los animales para la producción de leche. Por ejemplo, el bmh-T posee altas temperaturas $\left(>24^{\circ} \mathrm{C}\right)$ y precipitaciones que sobrepasan los $7000 \mathrm{~mm} / \mathrm{año}$, condiciones adversas que ocurren en regiones como Sarapiquí, San Carlos y Tortuguero. Por otro lado, el bp-MB, ubicado en las partes bajas de la Cordillera de Talamanca se caracteriza por una alta humedad y altas precipitaciones (4000-8000 mm/año) (Quesada 2007). Las circunstancias climáticas, observadas en dichas zonas ecológicas, no brindan el mejor entorno nutricional, ya que la calidad de forrajes no es la óptima, además del estrés calórico al que se enfrentan los animales; adicionalmente, el desarrollo de terneras en estas áreas del país es de tipo extensivo, es decir, sin los cuidados necesarios para lograr el máximo potencial genético de la hembra en su crecimiento y desarrollo hasta la pubertad y primer parto.

El bosque muy húmedo-Montano (bmh-M), ubicado en las faldas del Volcán Irazú y en el Cerro Chirripó (Quesada 2007), con temperaturas ambientales promedio de 6 a $11^{\circ} \mathrm{C}$ y precipitaciones entre 1000 y 2000 $\mathrm{mm} / \mathrm{año}$, presentó, de igual forma, uno de los más bajos niveles de producción (Vargas y Ulloa 2008).

Respecto al efecto de las variables reproductivas sobre la producción láctea, se determinó que aquellos animales sin retención de membranas fetales (RMF) tuvieron una producción de $450 \mathrm{~kg}$ más $(\mathrm{P}=0,0022)$ que aquellos que presentaron RMF (Cuadro 3). Este resultado concuerda con lo anteriormente reportado por Haworth et al. (2008), quienes afirman que complicaciones de parto, pueden implicar un deterioro de la posterior producción láctea del animal. Asimismo, los animales con lactancias de duración corta a media presentaron, respectivamente, una producción de $1350,65 \mathrm{~kg}$ y $253,00 \mathrm{~kg}$ menos $(\mathrm{P}<0,0001)$ que hembras con lactancias largas (Cuadro 3 ).

$\mathrm{Al}$ considerar el efecto del índice de endogamia, en conjunto con las demás variables, sobre la producción de la primera lactancia, no hubo diferencia significativa entre los animales con menos y más de
6,25\% de endogamia, así como tampoco lo hubo con las vacas con parto normal o difícil (Cuadro 3). Este resultado, es distinto de lo que menciona Thompson et al. (2000), quienes reportan que altos índices de endogamia producen un deterioro marcado del rendimiento productivo, de alrededor de 0,5 y $1,5 \mathrm{~kg}$ menos de leche por día.

\section{Efecto conjunto de la edad al primer y segundo parto, junto con variables de tiempo, lugar y ani- mal sobre la variable producción a 305 días de la segunda lactancia}

En la producción a 305 días de la segunda lactancia, algunas variables de tiempo, lugar y animal afectan de forma similar a lo que presenta la primera lactancia. Así, la EPP, influyó en la producción a 305d de la segunda lactancia, dando como resultado que las hembras con una baja EPP, presentaron una producción mayor $(143,6 \mathrm{~kg})$, en relación a aquellas que tuvieron una alta EPP. Asimismo, aquellas hembras que parieron por primera vez a una edad media, produjeron 74,6 kg más que las hembras con mayor edad al primer parto, aunque de forma no estadísticamente significativa $(\mathrm{P}=0,15)$ (Cuadro 4).

En relación al efecto de la EPP provocado sobre la producción de la segunda lactancia, esta influyó de una manera menos significativa que en la primera. El resultado concuerda con lo reportado por Haworth et al. (2008), donde se establece que la EPP no parece tener el mismo efecto que tiene en la primera lactancia, en las posteriores lactaciones pero, de igual manera, las hembras con una EPP baja, mantuvieron niveles de producción inferiores en 126,84 kg, que aquellas que llegaron a su primer parto a una edad más avanzada, cuya producción a 305 días correspondió a 4663,54 $\mathrm{kg}$. De igual manera, una baja EPP compromete el índice de longevidad dentro del hato (Haworth et al. 2008).

Al analizar el efecto de la variable ecozona, se comprobó una importante diferencia en las vacas del bp-P, con una producción de $728,85 \mathrm{~kg}$ por encima a la obtenida en la zona bmh-M ( $\mathrm{P}<0,0001)$. Por otro lado, las demás ecozonas mostraron un aumento de la producción que varió entre los 26 a $450 \mathrm{~kg}$ en comparación a bmh-M; únicamente la zona bp-MB presentó una diferencia negativa de $383,03 \mathrm{~kg}$ con respecto a la zona bmh-M (P= 0,0097) (Cuadro 4). 
Cuadro 4. Efecto de la edad al primer y segundo parto, y de variables de tiempo, lugar y animal sobre la producción a 305 días de la segunda lactancia, en vacas Jersey puras de hatos lecheros especializados de Costa Rica. Enero de 2000 a diciembre de 2010.

\begin{tabular}{|c|c|c|c|c|c|}
\hline Variable & Estrato & Estimado & Diferencia & E.E* & $\mathbf{P} * *$ \\
\hline Intercepto & & 5767,69 & & 296,05 & $<0,0001$ \\
\hline \multirow[t]{7}{*}{ Zona } & bh-MB & 4472,25 & 31,96 & 151,90 & 0,8333 \\
\hline & bh-P & 4714,92 & 274,64 & 152,59 & 0,0720 \\
\hline & bmh-P & 4895,52 & 455,24 & 154,24 & 0,0032 \\
\hline & bmh-T & 4466,66 & 26,38 & 148,34 & 0,8588 \\
\hline & bp-MB & 4057,25 & $-383,03$ & 148,09 & 0,0097 \\
\hline & bp-P & 5169,13 & 728,85 & 158,90 & $<0,0001$ \\
\hline & bmh-M & 4440,28 & . & . & . \\
\hline \multirow[t]{2}{*}{ Tipo de parto } & Normal & 4617,04 & 29,51 & 131,78 & 0,8228 \\
\hline & Distócico & 4587,53 & . & . & . \\
\hline \multirow[t]{2}{*}{ Retención } & Sin RMF & 4557,99 & $-88,59$ & 194,38 & 0,6486 \\
\hline & Con RMF & 4646,58 & . & . & . \\
\hline \multirow[t]{3}{*}{ ESP } & $<38,3$ & 4536,70 & $-126,84$ & 129,77 & 0,3284 \\
\hline & $38,3,54,3$ & 4606,63 & $-56,90$ & 120,60 & 0,6372 \\
\hline & $>54,3$ & 4663,54 & . & . & . \\
\hline \multirow[t]{3}{*}{ Días de lactancia 2} & $<252$ & 3747,66 & $-1436,38$ & 46,28 & $<0,0001$ \\
\hline & $252-355$ & 4875,16 & $-308,88$ & 31,35 & $<0,0001$ \\
\hline & $>355$ & 5184,04 & . & . & . \\
\hline \multirow[t]{2}{*}{ Endogamia } & $<6,25 \%$ & 4572,48 & $-59,61$ & 36,94 & 0,1066 \\
\hline & $>6,25 \%$ & 4632,10 & . & . & . \\
\hline \multirow[t]{3}{*}{ EPP } & $<25,8$ & 4673,13 & 143,59 & 62,44 & 0,0215 \\
\hline & $25,8-41$ & 4604,18 & 74,63 & 52,42 & 0,1546 \\
\hline & $>41$ & 4529,55 & . & . & . \\
\hline \multirow[t]{3}{*}{ kg 305 días $1^{\circ}$ lactancia } & $<2400$ & 4398,82 & $-687,13$ & 128,10 & $<0,0001$ \\
\hline & $2400-4302$ & 4322,09 & $-763,83$ & 33,98 & $<0,0001$ \\
\hline & $>4302$ & 5085,95 & . & . & . \\
\hline \multirow[t]{3}{*}{ Días Seca en la $1^{\circ}$ lactancia } & $<52$ & 4404,28 & $-314,90$ & 53,85 & $<0,0001$ \\
\hline & $52-82$ & 4683,40 & $-35,78$ & 46,40 & 0,4407 \\
\hline & $>82$ & 4719,18 & . & . & . \\
\hline \multirow{3}{*}{$\begin{array}{l}\text { Días de lactancia en la } 1^{\circ} \text { lac- } \\
\text { tancia }\end{array}$} & $<255$ & 4489,74 & $-209,78$ & 66,66 & 0,0017 \\
\hline & $255-343$ & 4617,59 & $-81,93$ & 35,83 & 0,0223 \\
\hline & $>343$ & 4699,53 & . & . & . \\
\hline
\end{tabular}

*EE= error estándar de la diferencia. ** $\mathrm{P}=$ valor de $\mathrm{P}$ de la diferencia.

$\mathrm{EPP}=$ edad a primer parto. $\mathrm{ESP}=$ edad al segundo parto.

bh-MB= bosque húmedo montano bajo bh- $\mathrm{P}=$ bosque húmedo premontano; bmh- $\mathrm{P}=$ bosque muy húmedo premontano; bmh- $\mathrm{T}=$ bosque muy húmedo tropical; bp-MB= bosque pluvial montano bajo; bp- $\mathrm{P}=$ bosque pluvial premontano; bmh-M= bosque muy húmedo montano. 
Respecto al efecto de algunas variables reproductivas sobre la producción a 305 días, se observó que el tipo de parto, la RMF y la ESP, no representaron efectos significativos (Cuadro 4).

La duración de la lactancia presentó diferencias entre aquellas lactancias cortas y medias, que produjeron $1436,38 \mathrm{~kg}$ y $308,88 \mathrm{~kg}$ menos, que las que lactaron por periodos más amplios $(\mathrm{P}<0,0001)$ (Cuadro 4).

$\mathrm{Al}$ igual que para la producción en la primera lactancia, no se observaron diferencias significativas en la producción a 305 días, entre los animales con grado de endogamia mayor o menor a 6,25\% (Cuadro 4).

La producción a 305 días de la primera lactancia si afectó de manera significativa la producción de la lactancia posterior; así, los animales con producciones bajas y medias durante la primera lactancia, produjeron menos leche en la segunda $(\mathrm{P}<0,0001)$ (Cuadro 4). Este hallazgo indica que el criterio popular de muchos productores, de que no importa que la novilla llegue con un desarrollo inferior al deseable a su primer parto, pues recuperan condición y desarrollo corporal durante la primera lactancia, de modo que en la segunda se igualan con las restantes, no es correcto y, más bien, está induciendo a los productores a perder importantes cantidades de leche $\mathrm{y}$, por consiguiente, de dinero.

Por otra parte, las vacas con menos días secos obtuvieron una producción inferior que los que obtuvieron un periodo seco más extenso $(p<0,0001)$ (Cuadro 4). Finalmente, los animales con lactancias de corta y media duración presentaron una producción inferior (210 kg y $82 \mathrm{~kg}$ aproximadamente) respecto a los animales con lactancias largas (Cuadro 4); que no son diferencias tan importantes como las observadas en la producción de la primera lactancia (Cuadro 3).

Hubo un efecto lineal de la EPP sobre la producción de leche de la primera y la segunda lactancia; más no un efecto de una ESP sobre la producción subsecuente. El detrimento de la EPP, conlleva a una marcada disminución de la producción láctea en la primera lactancia y, por una incapacidad de explotar su máximo potencial genético de producción, se ven afectadas sus lactancias posteriores.

La producción de la segunda lactancia, no se afecta por la EPP, igual que la primera, pero hembras con bajo rendimiento en su primer parto, mantuvieron bajos niveles de producción en la segunda. De ese modo, la EPP, parece tener un efecto no solo sobre la primera lactancia, sino también, en el rendimiento productivo posterior.

\section{LITERATURA CITADA}

Andrade, M. 2006. Evaluación de técnicas de manejo para mejorar la utilización del pasto kikuyo (Pennisetum clandestinum Hochst. Ex Chiov) en la producción de ganado lechero en Costa Rica. Tesis de licenciatura, Universidad de Costa Rica. San José, Costa Rica. 225 p.

Andrews, AH. 2000. The health of dairy cattle. Blackwell Publishing. Oxford, Inglaterra. 359 p.

Bailey, T; Currin, J. 2009. Milk production evaluation in first lactation heifers. Doc. No. 404-285. Virginia Cooperative Extension, Virginia State University (en línea). Consultado 28 febrero 2013. Disponible en http:// pubs.ext.vt.edu/404/404-285/404-285_pdf.pdf

Ball, PJ; Peters, AR. 2004. Reproduction in cattle. 3 ed. Blackwell Publishing. Oxford, Inglaterra. 248 p.

Ben Gara, A; Bouraoui, R; Rekik, B; Hammami, H; Rouissi, H. 2009. Optimal age at first calving for improved milk yield and length of productive life in Tunisian Holstein cows. Am. Euras. J. Agronomy 2:162-167.

Bolívar, D; Echeverry, J; Restreppo, L; Cerón-Muñoz, M. 2009. Productividad de vacas Jersey, Holstein y Jersey/ Holstein en una zona de bosque húmedo montano bajo (Bh-MB). Livestock Research for Rural Development 21(6) (en línea). Consultado 24 enero 2011. Disponible en http://www.lrrd.org/lrrd21/6/boli21080.htm.

Bormann, J; Druet, T; Gengler, N; Wiggans, GR. 2002. Estimating effects of permanent environment, lactation stage, age and pregnancy on test-day yield. J. Dairy Sci. 85:263-284.

Carvajal, M; Valencia, ER; Segura, JC. 2002. Duración de la lactancia y producción de leche de vacas Holstein en el Estado de Yucatán México. Rev. Biomed. 13:25-31.

Casas, E; Tewolde, A. 2001. Evaluación de características relacionadas con la eficiencia reproductiva. Arch. Latinoam. Prod. Anim. 9:63-67.

Ettema, J; Santos, J. 2004. Impact of age at first calving on lactation, reproduction, health, and income in firstparity Holstein on commercial farms. J. Dairy Sci. 87:2730-2742.

García, TB; Casell, GB; Pearson, RE; Misztal, I. 2005. Comparisons of Holsteins with Brown Swiss and Jersey Cows. J. Dairy Sci. 88:790-796.

González, N; Boschini, F. 1996. Comportamiento de la producción de leche en hatos Holstein y Jersey del valle central de Costa Rica. Nutrición Animal Tropical 3:43-59.

Hare, E; Norman, H; Wright, J. 2006. Trends in calving age and calving intervals for Dairy cattle breeds in the United States. J. Dairy. Sci. 89:365-370.

AGRONOMÍA MESOAMERICANA 24(1):177-187. 2013 
Haworth, G; Tranter, W; Chuck, J; Cheng, Z; Wathes, V. 2008. Relatioships between age at first calving and first lactation milk yield, and lifetime productivity and longevity in dairy cows. Vet. Rec. 162:643-647.

Heinrichs, AJ; Heinrichs, BS; Harel, O; Rogers, GW; Place, NT. 2005. A prospective study of calf factors affecting age, body size, and body condition score at first calving of Holstein dairy heifers. J. Dairy Sci. 88:2828-2835.

Holdrige, LR. 1987. Ecología basada en zonas de vida. Trad. por Humberto Jiménez Saa. San José, Costa Rica. IICA. 216 p.

Macdonald, KA; Penno, JW; Bryant, AM; Roche, JR. 2005. Effect of feeding level pre- and post puberty and body weight at first calving on growth, milk production and fertility in grazing dairy cows. J. Dairy Sci. 88: 3363-3375.

Marini, PR; Charmandarian, A; Oyarzabal, MI. 2001. Indicadores productivos y reproductivos de vacas de diferentes edades al primer parto en sistemas de pastoreo. ALPA Com. 9:345-348.

Marini, PR. 2004. Comportamiento de vacas de diferentes edades al primer parto. Ach. Zootec. 53:205-208.

Marini, PR; Charmandarian, A; Di Masso, RJ. 2007. Desempeño productivo y reproductivo de vacas de diferentes edades al primer parto en sistemas a pastoreo. Sitio Argentino de Producción Animal (en línea). Consultado 14 enero 2011. Disponible en http://www. produccion-animal.com.ar/.

Meyer, M; Everett, R; Van Amburgh, M. 2004. Reduced age at first calving: effects on lifetime production, longevity and profitability. Arizona Dairy (en línea). Consultado 12 enero 2011. Disponible en http://cals .arizona.edu.

NRC (National Research Council). 2001. Nutrient requirements of dairy cattle. 7 ed. National Academy Press. USA. 450 p.

Noordhuizen, JPTM: Buurman, J. 1984. Veterinary automated management and production control program for dairy farms (VAMPP). The application of MUMPS for data processing. Vet Q. 6:62-77.

Pirlo, G; Miglior, F; Speroni, M. 2000. Effect of age at first calving on production traits and on difference between milk yield returns and rearing costs on Italian holsteins. J. Dairy Sci. 83:603-608.

Powell, R. 1985. Trend of age at first calving. J. Dairy Sci. 68:768-772.
Quesada, R. 2007. Los bosques de Costa Rica. In Memorias del IX Congreso Nacional de Ciencias: Exploraciones fuera y dentro del aula. Instituto Tecnológico de Costa Rica, Cartago (en línea). Consultado 10 enero. 2012. Disponible en http://www.cientec.or.cr/exploraciones/ ponencias2007/RupertoQuesada.pdf

Radostits, O. 2001. Herd health: food animal production medicine. 3 ed. W.B. Saunders Company. Pennsynlvania, USA. 884 p.

SAS (Statistical Analysis System). 2009. SAS/STAT User's guide: Statistics. Version 9.2. Cary, NC, USA. 943 p.

Sejrsen, K; Purup, S. 1997. Influence of prepubertal feeding level in milk yield potential of dairy heifers: A review. J. Anim. Sci. 75:828-835.

Solano, C; Vargas, B. 1997. El crecimiento de novillas de reemplazo en fincas lecheras de Costa Rica: el efecto de la velocidad de crecimiento y edad al primer parto sobre la subsecuente producción de leche. Arch. Latinoam. Prod. Anim. 5:37-50.

Thompson, JR; Everett, RW; Wolfe, CW. 2000. Effects of inbreeding on production and survival in Jerseys. J Dairy Sci. 83:2131-2138.

USDA (United States Department of Agriculture). 2002. Dairy 2002, Part II: Changes in the United States dairy industry, 1991-2002. Rep. N399.0603. National Animal Health Monitoring System, Animal and Plant Health Inspection Service, USDA. Fort Collins, CO, USA. 49 p.

Vargas, B; Ulloa, J. 2008. Relación entre curvas de crecimiento y parámetros reproductivos en grupos raciales lecheros de distintas zonas agroecológicas de Costa Rica. Livestock Research for Rural Development 20 (7) (en línea). Consultado 10 enero 2012. Disponible en http://www.lrrd.org/lrrd20/7/varg20103.htm

Villalobos, L; Sánchez, JM. 2010. Evaluación agronómica y nutricional del pasto Ryegrass Perenne Tetraploide (Lolium perenne) producido en lecherías de las zonas altas de Costa Rica. II. Valor nutricional. Agronomía Costarricense 34:43-52.

West, J; Mullinix, B; Bernard, JK. 2003. Effects of hot, humid weather on milk temperature, dry matter intake. J. Dairy Sci. 86:232-242.

WingChing-Jones, R; Pérez, R; Salazar, E. 2008. Condiciones ambientales y producción de un hato de ganado Jersey en el Trópico Húmedo: el caso del módulo lechero SDA/UCR. Agronomía Costarricense 32:87-94. 
